\title{
COVID-19 Vaccination Certificates and Their Geopolitical Discontents
}

\author{
Tsung-Ling LEE* ${ }^{*}$
}

\begin{abstract}
At the international level, proof of vaccination against SARS-CoV-2 offers an enticing promise to the return of normality, particularly for the much-desired reopening of national borders. At the same time, vaccination passports could be a false hope: the requirement of vaccine passports could adversely embed social and economic inequalities that reflect the power dynamics in international relations. Specifically, the ability to secure vaccines relates to the varying market and economic power across countries. This paper focuses on Taiwan as a case study to explore ways in which the use of COVID-19 certifications, if used as a precondition for international travel, would further exacerbate a binary of exclusion and inclusion as a function of geopolitics. With its relative success in containing the COVID-19 pandemic within its borders, Taiwan represents a low priority for vaccine distribution in the COVAX initiative. Furthermore, due to Taiwan's contentious political status and its exclusion from the World Health Organization regime, if vaccination passports are required as a precondition for international travel, then outbound passengers from Taiwan potentially could be subjected to restriction of movement absent wide availability of vaccines domestically. This paper argues that insofar as sustainable pandemic control requires a global concerted effort, vaccination passports could further polarise a global response. This paper suggests that equitable access to effective vaccines worldwide and governance reform of global health would help to rebuild global solidarity and mitigate the unimaginable human, social and economic suffering arising from the pandemic.
\end{abstract}

\section{INTRODUCTION}

The once-in-a-century COVID-19 pandemic has caused unprecedented social, economic and political disruptions worldwide, with incalculable human costs and suffering. As of 27 May 2021, SARS-CoV-2 - the virus that is responsible for the pandemic - has resulted in 3.49 million deaths and 1.36 billion confirmed cases. ${ }^{1}$ According to the World Bank, the world economy shrank by $4.3 \%$ in 2020 as the COVID-19 pandemic engulfed the world. ${ }^{2}$ The International Monetary Fund (IMF) estimates that the global loss of

\footnotetext{
* Assistant Professor, Graduate Institute of Health and Biotechnology Law, Taipei Medical University; email: t1265@georgetown.edu. The research is supported by the Young Scholar Fellowship Program by Ministry of Science and Technology (MOST) in Taiwan, under Grant MOST109-2636-H038-002.

1 The Visual and Data Journalism Team, "Covid map: coronavirus cases, deaths, vaccinations by country" $(B B C)$ $<$ https://www.bbc.com/news/world-51235105> (last accessed 27 May 2021).

2 "Global Economic Prospects" (The World Bank, January 2021) < https://www.worldbank.org/en/publication/ global-economic-prospects $>$ (last accessed 27 May 2021).
} 
gross domestic product (GDP) from the pandemic is around USD 9 trillion, with approximately 88 and 115 million individuals having been pushed back into extreme poverty. ${ }^{3}$ As the world enters into the second year of the COVID-19 pandemic, vaccines against SARS-CoV-2 offer a concrete hope for returning to pre-pandemic normality, although the pandemic is still growing exponentially. To that end, for many countries, vaccine passports - defined for the purpose of this article as proofs of complete vaccination against SARS-CoV-2 to facilitate international travel - offer an enticing promise as a pathway to safely reopen economies and national borders. Yet the discussion on vaccine passports is not merely scientific but also a highly cultural and political affair, intensified by the urgent need to reboot economic activity and resume some level of "normality". As vaccines bring new hopes for the return to normality, new terms - vaccine diplomacy, vaccine nationalism and vaccine passports - have also entered the public discourse, reflecting a world deeply divided by wealth, ideological fault lines and the geopolitical dynamics that shape them.

As COVID-19 vaccines have reignited hopes for the world to return to some sort of prepandemic normality, Taiwan faces uncertainties over its ability to secure sufficient vaccines for its entire population to achieve herd immunity. These uncertainties loom over the country's hope for resuming international travel as the world has begun to explore the possibility of vaccine passports. Although Taiwan has enjoyed global recognition for the relative success of its pandemic response, a sudden spike in local cases beginning in late April looms over its previous success - as of 27 May 2021, Taiwan, a self-governing island of 23.5 million, has recorded 6761 cases and 59 deaths ${ }^{4}$ - and it currently faces challenges relating to vaccine procurement, largely as a function of geopolitics. Such challenges risk being compounded as the global discussion gets underway over the potential use of vaccine passports as a pathway to a safer reopening of national borders. This article focuses on Taiwan as a case study to examine the exogenous and endogenous factors that shape the conditions of possibility for vaccine passports, highlighting some of the geopolitical fault lines within the global supply of vaccines.

The uneven distribution of vaccines across countries (with vaccines tending to concentrate in the hands of wealthy countries in the Global North) and the unique circumstances faced by Taiwan since the island nation is excluded from participating at the World Health Organization (WHO) - largely because of its contentious political status - reveal a global health landscape that is as much fractured as it is fragmented. As countries are contemplating the domestic use of vaccine certifications and possibly extending them to international travel, this article highlights how the latter is profoundly shaped by the geopolitics that underpins countries' access to vaccines and the myriad legal and ethical concerns herein.

\footnotetext{
Fifth Meeting of the Panel Meeting Report, 17-18 March 2021, The Independent Panel for Pandemic Preparedness and Response <https://theindependentpanel.org/wp-content/uploads/2021/04/5thMeeting-Report_Final-1.pdf > (last accessed 27 May 2021).

4 "CECC confirms 2 more imported cases; cases arrive in Taiwan from the Philippine and Croatia" (Taiwan Centers for Disease Control, 16 April 2021) < https://www.cdc.gov.tw/En/Bulletin/Detail/T-3g81s6WU6YD7fSYG5FyA? typeid $=158>$ (last accessed 27 May 2021).
} 
This article proceeds as follows: it first provides a brief background on vaccine passports; second, it focuses on Taiwan as a case study to explore the cross-strait geopolitical tension as it unfolds at the national, regional and international levels; and third, it highlights the WHO's stance on the issue at present. This article concludes that the equitable distribution of vaccines would be a prerequisite for the use of vaccine passports. However, bold governance reform of global health might be needed to address the dysfunctional global health system as exposed by the COVID-19 pandemic in order to build a more equal post-pandemic world.

\section{VACCINE PASSPORTS: BACKGROUND}

Currently, there are ninety-one vaccines in clinical trials on humans, with twenty-seven having reached phase 3 of large-scale efficacy tests. ${ }^{5}$ The Pfizer COVID-19 vaccine (BNT162b2) was the first vaccine to receive the WHO's Emergency Use Listing (EUL) for SARS-CoV-2, having recently been joined by the two versions of the AstraZeneca/ Oxford COVID-19 vaccine manufactured by the Serum Institute of India and SKBio, the COVID-19 vaccine Ad26.COV2.S developed by Janssen (Johnson \& Johnson) and the Moderna vaccine (mRNA-1273) developed by Moderna. ${ }^{6}$ On 7 May 2021, the WHO granted emergency use authorisation to China's Sinopharm. Other vaccines that have applied for WHO EULs include Russia's Sputnik V and China's Sinovac. ${ }^{7}$ The Pfizer COVID-19 vaccine and the Moderna vaccine have also been approved for emergency use in the USA, the European Union (EU) and elsewhere. ${ }^{8}$ Clinical data suggest that these vaccines have varying efficacy in preventing the acquisition and transmission of SARS-CoV-2, ranging from $50 \%$ to $90 \%$, although all approved vaccines prevent the most severe forms of the disease and hospitalisation. Nevertheless, at the time of writing, there is insufficient scientific evidence on the duration of protection offered by these SARS-CoV-2 vaccines, as well as on the extent to which these vaccines prevent the acquisition and transmission of variants of SARS-CoV-2. It is also important to note that a conceptual difference exists between immunity and vaccine passports: the former refers to the detection of antibodies to SARS-CoV-2, ${ }^{9}$ while the latter refer to proofs of full vaccination against the virus as a condition for international travel. ${ }^{10}$

5 C Zimmer, J Corum and S-L Wee, "Coronavirus vaccine tracker" (New York Times) <https://www.nytimes.com/ interactive/2020/science/coronavirus-vaccine-tracker.html> (last accessed 27 May 2021).

6 "Coronavirus disease (COVID-19): vaccines" (World Health Organization) < https://www.who.int/news-room/ q-a-detail/coronavirus-disease-(covid-19)-vaccines > (last accessed 27 May 2021).

7 "Status of COVID-19 vaccines within WHO EUL/PQ evaluation process" (World Health Organization, 20 January 2021) < https://extranet.who.int/pqweb/sites/default/files/documents/Status_COVID_VAX_20Jan2021_v2.pdf > (last accessed 27 May 2021).

8 Zimmer et al, supra, note 5.

9 “'Immunity passports' in the context of COVID-19" (World Health Organization, scientific brief, 24 April 2021) <https://www.who.int/news-room/commentaries/detail/immunity-passports-in-the-context-of-covid-19> (last accessed 27 May 2021).

10 ibid. For a brief history on the use of vaccine passports, see F Kritz, "The vaccine passport debate actually began in 1897 over a plague vaccine" (NPR, 8 April 2021) <https://www.npr.org/sections/goatsandsoda/2021/04/08/985032748/ the-vaccine-passport-debate-actually-began-in-1897-over-a-plague-vaccine?utm_medium =social\&utm_term=nprnews\& utm_campaign=npr\&utm_source=facebook.com\&fbclid=IwAR1EGLNAs74nBsd3DwA1H42HNaT2HAfuJojwLK9tb 2c42KCVItMFwGxxPTU > (last accessed 17 April 2021). 
At the time of writing, the COVID-19 Vaccine Global Access Facility (COVAX) co-led by the WHO, Gavi (a public-private partnership focused on improving global access to immunisation) and the Coalition for Epidemic Preparedness Innovations has delivered 71 million doses to 125 countries, currently falling short of its target of 2 billion by the end of $2021 .^{11}$ The overall global distribution of vaccines remains uneven: of 1.6 billion doses administrated worldwide, $60 \%$ are concentrated in the advanced economies, with the majority being secured through Advanced Purchase Agreements. ${ }^{12}$ Canada, for example, has enough vaccines for nearly six times its population. The political economy of COVID-19 vaccine distribution thus reflects a deeply divided world where vaccine passports, if improperly administered, could further perpetuate global patterns of exclusion. Insofar as the equitable distribution of vaccines remains a key determinant of the rate of worldwide recovery from the pandemic, the discourse on vaccine passports as infused by geopolitics may mask the deeper structural issues (eg the monopoly of knowledge through intellectual property protection, global inequalities, governments' failures in strengthening public healthcare capacities) that have predated the emergence of COVID-19. While the Biden administration has announced the USA's commitment to waving patent protections for COVID-19 vaccines at the World Trade Organization ${ }^{13}$ and the G20 leaders have suggested voluntary licensing instead, ${ }^{14}$ the world would still need to expand global manufacturing capability and facilitate the necessary knowledge transfer to have a real impact.

Caught in the strategic competition and economic rivalry between the USA and China, Taiwan's peculiar international status reflects a binary world of inclusion and exclusion. Insofar as the discussion of vaccine passports is closely interwoven with the rhetoric of vaccine diplomacy, it also reveals increased geopolitical tensions around the world. New terms - such as "vaccine apartheid" and "vaccine nationalism" - that have entered the public discourse over the past year reflect anxieties surrounding the global health political economy more broadly. The emergence of these new terms also reflects a dysfunctional global health system, which some scholars perceive as a legacy of colonialism that embeds current global inequalities. ${ }^{15}$ As current hopes for returning to normal public life hinge upon vaccinating the population swiftly, the myriad legal and ethical concerns surrounding the rollout of vaccine passports (including the encroachment on privacy and autonomy, the growing digital divide and the deepening of inequalities) must also be considered within a wider discussion of other forms of international inequality in a multipolar world.

\footnotetext{
11 COVAX has so far shipped over 71 million COVID-19 vaccines to 125 participants < https://www.gavi.org/covaxvaccine-roll-out $>$ (last accessed 27 May 2021).

12 Zimmer et al, supra, note 5.

13 A Maxmen, "In shock move, US back waiving patents on COVID vaccines" (Nature) <https://www.nature.com/ articles/d41586-021-01224-3> (last accessed 27 May 2021).

14 F Guarascio, "G20 leaders to back COVID-19 vaccine voluntary licensing, no patent waiver" (Reuters) <https:// www.reuters.com/business/healthcare-pharmaceuticals/drugmakers-make-big-low-cost-vaccine-push-poor-nationseu-official-2021-05-20/> (last accessed 27 May 2021).

15 JB Bump, F Baum, M Sakornsin, R Yates and K Hofman, "Political economy of COVID-19: extractive, regressive, competitive" (2021) 372 BMJ 73 <https://www.bmj.com/content/372/bmj.n73> (last accessed 27 May 2021).
} 


\section{TAIWAN AND ITS LONG ROAD TO VACCINATION}

Within Taiwan, the discussion over digital vaccine passports remains relatively limited compared to in other countries, partly because of the relative success of the domestic pandemic response that has diminished the urgency for the government to reopen its borders as long as the situation remains dire internationally. Like its neighbours in East Asia such as Japan and South Korea, Taiwan's pandemic response consists of the strong enforcement of traditional public health measures (eg universal face mask wearing, effective contact tracing) that, combined with digital technology, have proved largely effective at containing the spread of SARS-CoV-2. As an island nation, border control is relatively easy in Taiwan as compared to other countries with land borders. Taiwan adopted a risk-based approach to international border control when SARS-enCoV-2 was first identified in Wuhan, China. Instead of outright prohibiting the entry of inbound passengers from China, Taiwan first implemented on-board inspection of inbound passengers from Wuhan, then expanded to the temporary suspension of the entrance of foreign nationals from China. ${ }^{16}$

In many ways, Taiwan's strict enforcement of traditional public health measures which was not without criticism ${ }^{17}$ - yielded successful pandemic management until late April 2021. Strict border control measures - where inbound passengers are required to undergo fourteen days of mandatory quarantine either in designated hotels or at homes, for instance - have kept the country relatively free of SARS-CoV-2. ${ }^{18}$ However, as mandatory quarantine days were relaxed for flight crews in April 2021, cluster of cases soon erupted, mostly concentrated in the two major cities in Taiwan.

Like elsewhere, the Taiwanese government also faces political pressure to reopen, particularly as the island has close economic ties with China. ${ }^{19}$ Even though the markedly low number of cases attests to Taiwan's effective pandemic management and response so far, challenges are ahead. Prior to the outbreak that began in late April, the island's pandemic response has been exemplary in many aspects; this also meant that Taiwan had a lower priority for vaccine distribution through the COVAX Facility when compared to other countries and economies - and rightly so, as the Facility prioritises vaccines in terms of the "most in need" instead of "most in want" worldwide. Yet the recent outbreak in Taiwan underscores the difficult of achieving total elimination of SARS-CoV-2 without vaccines. If the reopening of international travel is premised on the condition of vaccination passports, this could also exacerbate the global shortage in vaccines and would adversely reward those countries with market power and access to vaccines, further diminishing the already limited global solidarity.

\footnotetext{
16 Prevention and Control of COVID-19 in Taiwan (Taiwan Centers for Disease and Control) <https://www.cdc.gov. tw/en/category/page/0vq8rsAob_9HCi5GQ5jH1Q> (last accessed 27 May 2021).

17 See, eg, Digital surveillance and the erosion of democracy, Taiwan Association for Human Rights <https://www. tahr.org.tw/news/2613> (last accessed 27 May 2021).

18 H Tzu-ti, "Taiwan economy to expand 5.9\% in 2021: JP Morgan” (Taiwan News, 26 February 2021) <https:// www.taiwannews.com.tw/en/news/4136974> (last accessed 17 April 2021).

19 Editorial, "Editorial: Ma playing politics with vaccines" (Taipei Times, 19 February 2021) <https://www. taipeitimes.com/News/editorials/archives/2021/02/19/2003752481> (last accessed 27 May 2021).
} 
Cross-strait tensions also inform the domestic vaccine discourse, which is also strongly shaped along geopolitical lines. The opposition party, Kuomintang (KMT), which has a pro-China stance, has also made the party a strong advocator for Chinese-made vaccines. ${ }^{20}$ This is despite China's Sinovac having a reported efficacy of around $50 \%$ in both Brazil and Chile. ${ }^{21}$ Recently, the Chinese Center for Diseases Control and Prevention has acknowledged that Chinese-manufactured vaccines fall short of expected efficacy. ${ }^{22}$ As the scientific validity of these Chinese-made vaccines is widely questioned, the Taiwanese government has repeatedly rejected the KMT's proposal based on scientific grounds. ${ }^{23}$ Domestically, the law prohibits the importation of Chinese-made vaccines and other biological products. ${ }^{24}$ However, former President Ma Ying-Jeou, of KMT, has claimed that the government has rejected the Chinese-made vaccines based on political grounds alone. ${ }^{25}$ Nonetheless, public acceptance of Chinese-manufactured COVID-19 vaccines remains low according to one report. ${ }^{26}$

Like elsewhere in the world, imported vaccines still need to undergo a rigorous regulatory process, with an Emergency Use Authorisation granted for the AstraZeneca vaccine on 20 February $2021 .{ }^{27}$ Currently, around than 517,000 doses of the AstraZeneca vaccine are available island-wide, making it the only vaccine available for preventing SARS-CoV-2 in Taiwan. However, the uptake for the AstraZeneca vaccine has been overshadowed by its linkage with rare blood clots, which adds to widespread vaccine hesitancy ${ }^{28}$; however, the recent outbreak has also seen a surge in demand, especially amongst first-line healthcare workers. Overall, the island remains vulnerable to the virus, as only $1 \%$ of the population is vaccinated, largely due to the low availability of vaccine supplies. ${ }^{29}$

Attempts to secure the Pfizer COVID-19 vaccine manufactured by Germany's BioNTech has met with notable difficulties, where the ability to secure and distribute

\footnotetext{
20 B Hioe, "KMT begins to call for Tsai administration to accept Chinese COVID-19 vaccines" (New Bloom, 25 February 2021) < https://newbloommag.net/2021/02/24/kmt-chinese-vaccines/> (last accessed 17 April 2021).

21 E Dou and S Mahtani, "China's vaccine diplomacy stumbles as clinical trial data remains absent" (The Washington Post, 23 March 2021) <https://www.washingtonpost.com/world/asia_pacific/china-coronavirus-singapore-data/2021/ 03/23/7a0582ca-8afc-11eb-a33e-da28941cb9ac_story.html> (last accessed 27 May 2021).

22 G Shih, "Effectiveness of Chinese vaccines 'not high and needs improvement', top health official says" (The Washington Post, 11 April 2021) <https://www.washingtonpost.com/world/asia_pacific/china-vaccine-efficacy-nothigh-gao/2021/04/11/dafe3ab6-9a8f-11eb-8f0a-3384cf4fb399_story.html> (last accessed 17 April 2021).

23 L I-chia, "Taiwan begins COVID-19 vaccinations" (Taipei Times, 23 March 2021) < https://taipeitimes.com/ News/front/archives/2021/03/23/2003754315> (last accessed 27 May 2021).

24 "Taiwan will not import COVID-19 vaccines made in China: minister" (Focus Taiwan, 27 September 2020) $<$ https://focustaiwan.tw/society/202009270014> (last accessed 27 May 2021).

25 Hioe, supra, note 20.

26 K Everington, "Only $1.3 \%$ of Taiwanese willing to take Chinese COVID vaccines" (Taiwan News, 24 February 2021) <https://www.taiwannews.com.tw/en/news/4134963> (last accessed 27 May 2021).

27 Reuters staff, "Taiwan grants emergency authorization for AstraZeneca COVID-19 vaccine" (Reuters, 21 February 2021) < https://www.reuters.com/article/us-health-coronavirus-taiwan-idUSKBN2AK05R> (last accessed 27 May 2021).

28 M Corder, "Governments give varying advice on AstraZeneca vaccine" (Taiwan News, 8 April 2021) <https:// www.taiwannews.com.tw/en/news/4172030> (last accessed 27 May 2021).

29 L Chung, "Taiwan's low coronavirus vaccination rate under scrutiny as it battles spike in cases" (South China Morning Post, 17 May 2021) <https://www.scmp.com/news/china/science/article/3133833/taiwans-low-covid-19vaccination-rate-under-scrutiny-it-battles $>$ (last accessed 27 May 2021).
} 
vaccines remains largely dependent on market power and, in Taiwan's case, political sway. While the government is reluctant to disclose the negotiation details with BioNTech, the media report that Taiwan's procurement of the Pfizer vaccine is also infused with geopolitics. According to media reports, possible pressure from China has made it less likely for Taiwan to be able to purchase the Pfizer vaccine from the manufacturer. ${ }^{30}$ For Taiwan, hopes of achieving herd immunity thus now hinge upon domestic production currently in clinical trials. ${ }^{31}$

To increase the voluntary uptake of vaccines, the Taiwanese government has increased public health campaigns and education. However, the vaccination rate remains slow, which can be explained by the vaccines' limited accessibility and availability, as well as the general public's perception of vaccine safety and effectiveness. Vaccine hesitancy remains a key barrier to the national vaccination efforts in Taiwan. According to one report, only $60.3 \%$ of Taiwanese citizens are willing to be vaccinated against SARS-CoV-2, which is below the international average of $74 \% .{ }^{32}$

At the same time - and as the COVID-19 pandemic stretches into a second year vaccine procurement has also become an ideological battlefield between liberal democratic states and authoritarian regimes. Caught in the crossfire between the USA and China, Taiwan's increased geopolitical importance and its relative success in pandemic management have made international headlines. ${ }^{33}$ Indeed, Taiwan's peculiar political status has become further complicated by the pandemic. China has long claimed Taiwan as part of its territory, a claim strongly disputed by Taiwan, as the country operates through an independent democratic system and has never been under the control of China. ${ }^{34}$ China has consistently wielded its political and economic influence on Taiwan through soft power: before the emergence of COVID19, China exerted considerable soft power over 400,000 Taiwanese businesses in China through tax incentives and considerable subsidies. During the pandemic, Chinese-produced vaccines became the latest state apparatus used to lure Taiwan, in that Taiwanese based in China were given priority for the Chinese COVID-19 vaccines. ${ }^{35}$ Such a tactic is consistent with China's overall vaccine diplomacy, which has seen over sixty countries granting approval for China's vaccines. ${ }^{36}$ China has also attempted to use vaccines to lure Paraguay and Honduras - two of Taiwan's limited

30 C-T Cheng, "Taiwan becoming less likely to purchase COVID vaccine from BioNTech" (Taiwan News, 29 March 2021) < https://www.taiwannews.com.tw/en/news/4163283> (last accessed 27 May 2021).

31 K Everington, "Taiwan to build vaccine plant to produce 20 million shots per month" (Taiwan News, 5 March 2021) < https://www.taiwannews.com.tw/en/news/4142851> (last accessed 17 April 2021).

32 P Ng, "With vaccines in hands, what's next for Taiwan's Covid-19 response?" (News Lens, 13 March 2021) $<$ https://international.thenewslens.com/article/148382> (last accessed 15 June 2021).

33 See, eg, J Rogin, "Opinion: the pandemic shows why Taiwan is a far better partner than the People's Republic" (The Washington Post, 8 May 2020) <https://www.washingtonpost.com/opinions/global-opinions/the-pandemic-showswhy-taiwan-is-a-far-better-partner-than-the-peoples-republic/2020/05/07/8af1e1c8-909d-11ea-a9c0-73b93422d691_ story.html > (last accessed 27 May 2021).

34 Reuters, "COVID-19 vaccines become latest front line in China's campaign to win hearts of Taiwanese" (The Strait Times, 21 January 2021) <https://www.straitstimes.com/asia/east-asia/covid-19-vaccines-become-latest-frontline-inchinas-campaign-to-win-hearts-of $>$ (last accessed 17 April 2021).

35 ibid.

36 Tzu-ti, supra, note 18. 
allies - to sever diplomatic ties with Taiwan. ${ }^{37}$ Despite the lingering doubts over the efficacy of these vaccines, the limited global supply chain for WHO-approved vaccines has seen countries - mostly lower-income countries - embracing the extension of China's "Health Silk Road" amidst the pandemic. ${ }^{38}$

Prior to the April outbreak, many commenters assumed that Taiwan's effective pandemic management meant that the island had the luxury of time not afforded to many countries that were in a race against time to vaccinate their populations swiftly. However, these views have been drastically challenged with the sudden spike in local cases. Although the government has acknowledged that vaccine passports might be on the horizon for the country, the government also experimented with travel bubbles with Palau, which has zero case of SARS-CoV-2 infection. ${ }^{39}$ Yet, as domestic cases increase daily in Taiwan, flights between Taiwan and Palau are also cancelled for now.

Yet, as population-wide vaccination becomes deemed to be a necessary pathway to mitigate the pandemic, while global vaccine supply remains limited vaccine passports risk becoming discriminatory based upon access. Introducing vaccine passports as a condition for entrance into a country could also lead to potentially discriminating against those with medical reasons not to be vaccinated (ie individuals who are immunocompromised or allergic to some vaccine components) or those who choose not to be vaccinated. Furthermore, if airlines or governments require digital vaccine passports as a requisite for boarding or entrance, this could also deepen the digital divide and potentially create a two-tier world based on vaccination status, as other papers in this special issue also argue.

At the regional level, the discourse on vaccine passports remains at an early stage in most East Asian countries. ${ }^{40}$ Nevertheless, there is a critical need to interrogate the use of vaccine passports for cross-border travel, whether at the regional or the international level. The discussion on the use of vaccine passports that has begun in the Association of Southeast Asian Nations (ASEAN) ${ }^{41}$ is in its early stages, but unlike in the EU, ASEAN regulations on data protection remain weak, adding a further layer of challenge in the ASEAN context. ${ }^{42}$

As others in this special issue note, at the national, regional and international levels, the discussion over digital vaccine passports may mask complex technological challenges as a deceptively simple solution to the reopening of international borders. However,

37 SF Pratt and J Levin, "Vaccines will shape the new geopolitical order" (Foreign Policy, 29 April 2021) < https:// foreignpolicy.com/2021/04/29/vaccine-geopolitics-diplomacy-israel-russia-china/> (last accessed 27 May 2021).

38 N Biyani and N Graham, "COVID vaccines: India and China's new diplomatic currency" (Atlantic Council) $<$ https://www.atlanticcouncil.org/blogs/new-atlanticist/covid-vaccines-india-and-chinas-new-diplomatic-currency/> (last accessed 27 May 2021).

39 "Taiwan-Palau travel bubble to start April 1: CECC" (Focus Taiwan, 17 March 2021) <https://focustaiwan.tw/ society/202103170017> (last accessed 27 May 2021).

40 M Landler, "Vaccine passports could unlock world travel and cries of discrimination" (New York Times, 9 April 2021) <https://www.nytimes.com/2021/04/09/world/europe/vaccine-passports-virus-issues-legal-ethical.html> (last accessed 17 April 2021). See also E Sugiura and S Tani, "Asian startups jump into developing vaccine passports" (3 May 2021) <https://asia.nikkei.com/Business/Startups/Asian-startups-jump-into-developing-vaccine-passports> (last accessed 27 May 2021).

41 G Lee and QS Jye, "Commentary a digital vaccine passport could open up Southeast Asia travel bubble but some changes needed first" (CNA, 9 April 2021) <https://www.channelnewsasia.com/news/commentary/asean-vaccinepassport-travel-border-open-covid-19-restriction-14580756> (last accessed 27 May 2021).

42 ibid. 
harnessing digital technology for vaccine passports must first overcome the considerable technological challenges ahead: first, different databases across countries must be made interoperable; second, access to countries' official records of complete vaccinations with links to individuals' health records must be secure and free from cyberattack; and third, a common standard across countries for cross-border health data transfer must be accepted. ${ }^{43}$ Likewise, legally, the use of digital vaccine passports will need to be in compliance with personal data protection regulations within the jurisdictions in which they operate (or, in most cases, also across jurisdictions). Privacy, data protection and autonomy risk being the first casualties if they are not addressed appropriately, as international pressure for adopting vaccine passports is building.

Protecting sensitive data remains a highly scrutinised issue in Taiwan. Previously, the government has planned to introduce a national scheme of digital identification cards, but the initiative was widely opposed chiefly due to the lack of legal safeguards to prevent unwarranted access by the government. ${ }^{44}$ As a result, the government has halted the initiative indefinitely. As the COVID-19 pandemic unfolds, the Taiwanese government has linked different databases to enable real-time disease surveillance, raising legal and ethical concerns. ${ }^{45}$ However, for now, vaccination status for SARS-CoV-2 is recorded on a physical card that is not linked to health records. It should also be noted that the Personal Data Protection Act (PDPA) that governs the collection, processing and use of personal data would also be applicable to the crossborder transfer of data if international vaccine passports are adopted in Taiwan, where the PDPA is based on the General Data Protection Regulation (GDPR) in the EU. ${ }^{46}$

\section{The World Health Organization and the politics of Global health}

Along with the exposure of geopolitical fault lines, the COVID-19 pandemic has shattered many assumptions about the ability of international organisations to achieve global cooperation when faced with collective action problems. Established in the aftermath of the Second World War, the WHO is tasked to act as the coordinating global health agency when infectious diseases of international concern arise. ${ }^{47}$ The WHO has thus far opposed the use of immunity passports against the background of diminishing trust and credibility, as the reputation of the agency has suffered considerably from its obvious missteps when the virus first emerged. ${ }^{48}$

\footnotetext{
43 "Covid passports: what are different countries planning?" (BBC, 26 March 2021) < https://www.bbc.com/news/ world-europe-56522408> (last accessed 27 May 2021).

44 "Digital ID card plan suspended" (Focus Taiwan, 21 January 2021) < https://focustaiwan.tw/society/ 202101210007> (last accessed 27 May 2021).

45 EJ Emanuel, C Zhang and A Glickman, "Learning from Taiwan about responding to Covid-19 - and using electronic health records" (STAT, 30 June 2020) < https://www.statnews.com/2020/06/30/taiwan-lessons-fightingcovid-19-using-electronic-health-records/> (last accessed 27 May 2021).

46 ibid.

47 UN General Assembly, Entry into force of the constitution of the World Health Organization, 17 November 1947, A/RES/131, available at < https://www.refworld.org/docid/3b00f09554.html> (last accessed 27 May 2021).

48 TJ Bollyky and SM Patrick, "improving pandemic preparedness: lessons from Covid-19" (Council on Foreign Relations) <https://www.cfr.org/report/pandemic-preparedness-lessons-COVID-19/findings/> (last accessed 15 June 2021).
} 
At the beginning of the pandemic, the WHO strongly advised against the use of immunity passports, citing the lack of scientific evidence to support their basis. ${ }^{49}$ One year on, at the sixth meeting of the International Health Regulations Emergency Committee for the COVID-19 pandemic, the WHO remains opposed to requiring proof of vaccination for international travellers. ${ }^{50}$ Drawing attention again to the concerns of vaccine equity and scientific validity, the WHO Director-General issued the following Temporary Recommendation under the Public Health Emergency of International Concern (PHEIC): "At the present time, countries should not introduce requirements of proof of vaccination or immunity for international travel as a condition of entry as there are still critical unknowns regarding the efficacy of vaccination in reducing transmission and limited availability of vaccines". ${ }^{51}$ For now, then, the WHO remains adamantly against introducing proof of vaccination as a condition of entry, which may exacerbate inequities across and within countries. ${ }^{52}$ The stance is reiterated in a WHO interim paper: "In the current context, introducing a requirement of vaccination as a condition for travel has the potential to hinder equitable global access to a limited vaccine supply and would be unlikely to maximize the benefits of vaccination for individual societies and overall global health". ${ }^{53}$ Nonetheless, most recently (and recognising the potential for facilitating the reopening of international borders), the WHO has formed a Smart Vaccination Certification Working Group due to the growing interest in harnessing digital technologies for documenting vaccination status. ${ }^{54}$

It is important to note that here the requirement of proof of vaccination as a condition for international travel under the 2005 International Health Regulations (IHR) - the governing legal architecture for international infectious diseases control for 196 countries - is not without precedent. In the past, the WHO's Yellow Card for cholera, plague and typhoid has been extensively used to verify the vaccination status of international travellers. ${ }^{55}$ While the IHR permit State Parties to implement additional health measures that "achieve the same or greater level of health protection than recommended by the WHO", these health measures must also be non-discriminatory, among other human rights considerations. Under the IHR, the requirement for vaccination is guided by Article 31 and is limited to specific diseases provided in

\footnotetext{
49 "Interim position paper considerations regarding proof of COVID-19 vaccination for international travellers" (World Health Organization, 5 February 2021) <https://www.who.int/news-room/articles-detail/interim-positionpaper-considerations-regarding-proof-of-covid-19-vaccination-for-international-travellers $>$ (last accessed 17 April 2021).

50 "Statement on the sixth meeting of the International Health Regulations (2005) Emergency Committee regarding the coronavirus disease (COVID-19) pandemic" (World Health Organization, 15 January 2021) <https://www.who.int/ news/item/15-01-2021-statement-on-the-sixth-meeting-of-the-international-health-regulations-(2005)-emergencycommittee-regarding-the-coronavirus-disease-(covid-19)-pandemic > (last accessed 17 April 2021).

51 Supra, note 49

52 "WHO does not back vaccination passports for now - spokeswoman" (Reuters, 6 April 2021) <https://www. reuters.com/article/us-health-coronavirus-who-vaccines-idUSKBN2BT158> (last accessed 27 May 2021).

53 Supra, note 49.

54 Smart Vaccination Certificate Working Group (World Health Organization) < https://www.who.int/groups/smartvaccination-certificate-working-group $>$ (last accessed 27 May 2021).

55 C Dye and MC Mills, “COVID-19 vaccination passports" (2021) 371(6535) Science 1184.
} 
Annex 7, specifically to yellow fever. ${ }^{56}$ The WHO could thus issue a temporary recommendation that is issued every three months when a PHEIC is declared, as in the case for poliovirus. Issuing a temporary recommendation would legally permit the use of vaccine passports internationally in the context of COVID-19. However, the WHO has stated that for the organisation to make such a recommendation it would need to be premised on the universal availability of vaccines, which must be approved under emergency use by the WHO. ${ }^{57}$

Despite being the global health agency, the WHO is not immune from geopolitics. With Sinopharm recently being added to the WHO's EUL with an efficacy rate of $78.1 \%$ - a win for China's geopolitical clout as perceived by some commentators ${ }^{58}$ it remains to be seen whether China will donate a sufficient amount to the COVAX Facility to help ease the global shortage of vaccines, as China also faces domestic shortage. ${ }^{59}$ Anti-Chinese sentiment that is prevalent in some South-East Asian countries such as in Vietnam, which is currently experiencing a surge in local cases, also underpins resistance to Chinese-made vaccines. ${ }^{60}$ Furthermore, the EU's exclusion of Chinese- and Russian-made vaccines from its soon-to-be-launched COVID-19 Certificate also marks challenges for the rollout of international vaccine passports.

\section{Conclusion}

Vaccine passports have raised many unanswered questions so far. The myriad legal and ethical concerns stemming from vaccine passports would need to be adequately addressed before considering them as a tool to reopen international borders. What is more, the global discord over vaccine supply and distribution may further embed geopolitical discontent vis-à-vis vaccine passports. Without addressing the issues raised in this article adequately, vaccine passports may not only engender and perpetuate global inequalities, but also further divide the world across geopolitical fault lines.

\footnotetext{
56 AL Phelan, "COVID-19 immunity passports and vaccination certificates: scientific, equitable, and legal challenges" (2020) 395(10237) The Lancet 1595-98.

57 Supra, note 49.

58 S-L Wee, "China's vaccine diplomacy just got a big win. But can the country deliver?" (New York Times, 7 May 2021 ) < https://www.nytimes.com/2021/05/07/business/economy/china-sinopharm-vaccine-who.html > (last accessed 27 May 2021).

59 ibid.

60 DNA Luong, "Vietnam may not want China's COVID-19 vaccines, but how long can it stay immune to them?" (South China Morning Post, 20 May 2021) <https://www.scmp.com/week-asia/opinion/article/3134085/vietnam-maynot-want-chinas-covid-19-vaccines-how-long-can-it> (last accessed 27 May 2021).
} 